\title{
Prognostic value of endocan expression in cancers: evidence from meta-analysis
}

\author{
This article was published in the following Dove Press journal: \\ OncoTargets and Therapy \\ 13 October 2016 \\ Number of times this article has been viewed
}

\author{
Xing Huang ${ }^{1, *}$ \\ Chen Chen ${ }^{2, *}$ \\ Xin Wang ${ }^{3, *}$ \\ Jing-yuan Zhang' \\ Bin-hui Ren ${ }^{3,4}$ \\ Da-wei $\mathrm{Ma}^{\prime}$ \\ Lei $X i{ }^{\prime}$ \\ Xin-yu $\mathrm{Xu}^{\prime}$ \\ $\operatorname{Lin} \mathrm{Xu}^{3,4}$
}

'Department of Pathology, Nanjing Medical University Affiliated Cancer Hospital, ${ }^{2}$ Second Clinical College of Nanjing Medical University, ${ }^{3}$ Department of Thoracic Surgery, Nanjing Medical University Affiliated Cancer Hospital, ${ }^{4}$ Jiangsu Key Laboratory of Molecular and Translational Cancer Research, Nanjing Medical University Affiliated Cancer Hospital, Nanjing, People's Republic of China

*These authors contributed equally to this work

\begin{abstract}
Endocan is a $50 \mathrm{kDa}$ dermatan sulfate proteoglycan. Numerous previous studies have indicated that endocan might be an attractive prognostic tumor biomarker. However, the results of different studies are inconsistent. We conducted a meta-analysis to explore the association between endocan expression and cancer prognosis. A systematic, comprehensive search of the PubMed, Embase, and China National Knowledge Infrastructure databases was performed. Expression of endocan and its association with overall survival were evaluated by pooled hazard ratios (HRs) and their 95\% confidence intervals (CIs). In total, 15 eligible studies of 1,464 patients were finally included in this meta-analysis. A significant association was found between elevated endocan expression and poorer overall survival (pooled HR: $2.48,95 \% \mathrm{CI}$ : 2.12-2.90, $P<0.001)$. In the cancer-type subgroup, significant associations were detected for gastrointestinal (HR: 2.27, 95\% CI: 1.77-2.91, $P<0.001$ ) and hepatocellular (HR: $2.61,95 \%$ CI: $1.96-3.48, P<0.001)$ carcinoma. Our results demonstrate that endocan could be useful to exploit as a novel prognostic biomarker for patients with cancer.
\end{abstract}

Keywords: endocan, ESM-1, biomarker, cancer, prognosis, meta-analysis

\section{Introduction}

Endocan, previously called endothelial cell-specific molecule-1, was first cloned by Lassalle et al in 1996 from a human umbilical vein endothelial cell complementary DNA library. ${ }^{1}$ It is a $50 \mathrm{kDa}$ dermatan sulfate proteoglycan, and is secreted by activated vascular endothelial cells, including tumor endothelial cells. ${ }^{2-4}$ Endocan can be upregulated by angiogenic factors and inflammatory cytokines, such as tumor necrosis factor- $\alpha$ and interleukin-1 $\beta .^{1,2}$ In previous studies, endocan was found to induce tumor formation and to be closely associated with the conversion of dormant tumors into fast-growing angiogenic tumors. ${ }^{5,6}$ Recent studies have shown that endocan is overexpressed at the messenger RNA and/or protein levels in various tumor types, including glioblastoma, ${ }^{7}$ pituitary adenoma, ${ }^{8,9}$ nonsmall cell lung cancer, ${ }^{10}$ gastric cancer, ${ }^{11-14}$ colorectal cancer,,${ }^{15-17}$ renal cell cancer, ${ }^{2,18}$ bladder cancer, ${ }^{19}$ ovarian cancer, ${ }^{20}$ and hepatocellular carcinoma. ${ }^{21-23}$ Most studies also suggested that endocan overexpression was associated with aggressive tumor progression and poor outcomes. ${ }^{7,11,13-17,20,21,23,24}$ However, conflicting results still exist. $^{12,19,22}$ Therefore, we conducted a meta-analysis of the available studies to investigate the relationship between endocan expression and prognosis of patients with cancer.

\section{Materials and methods Search and selection process}

A systematic literature search was conducted of the PubMed, Embase, and China National Knowledge Infrastructure databases, covering all relevant studies published 
up to September 22, 2015, using the following keywords: "endocan" OR "ESM-1" AND "prognosis" OR "survival" OR “outcome” AND “cancer" OR "carcinoma” OR "neoplasm." The reference lists of the relevant publications were also carefully reviewed to obtain additional information.

\section{Inclusion and exclusion criteria}

To be eligible for inclusion, studies had to meet the following criteria: (a) published as a full paper in the English or Chinese literature; (b) investigated the association between endocan expression and cancer prognosis; and (c) included sufficient data for estimating hazard ratio (HR) with $95 \%$ confidence interval (CI). The major reasons for exclusion of studies were: (a) overlapping or duplicate data; (b) publication was either an abstract, comment, or review; and (c) without detailed data. The flow diagram for the study is shown in Figure 1.

\section{Data extraction and quality assessment}

Two reviewers (XH and XW) performed the search and identification independently using a standard approach. ${ }^{25}$ The following items were extracted from each eligible publication: first author, year of publication, nationality, ethnicity (Asian or Caucasian), cancer type, quantitative method (enzyme-linked immunosorbent assay or immunohistochemistry), cutoff value, length of follow-up (months), HR with corresponding 95\% CI for overall survival (OS) or recurrence-free survival (RFS), and total number of participants. In cases of discrepancy, another investigator (B-HR) was invited to check and discuss the original data until a consensus was reached. Quality assessment for each study included in the final analysis was carried out by the same two reviewers (XH and XW) according to the Newcastle-Ottawa

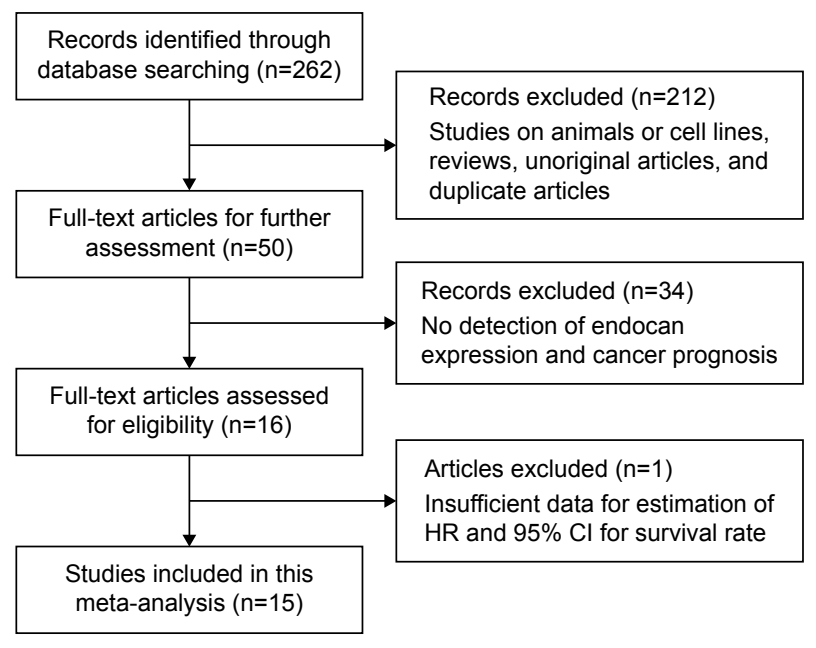

Figure I Study flow chart showing the process for selecting eligible publications. quality assessment scale (NOS). ${ }^{26}$ The Newcastle-Ottawa scores range from 0 to 9 , and a score of $\geq 6$ indicated good quality in the present study.

\section{Statistical analysis}

HR with 95\% CI was calculated for the association between endocan expression and cancer prognosis (OS and RFS). When the statistical variables were reported in the text or tables, we obtained them directly. Otherwise, the methods reported by Tierney ${ }^{27}$ were used to calculate data from Kaplan-Meier survival curves. Heterogeneity between studies was checked using the $\chi^{2}$-based $Q$-test and considered statistically significant at $I^{2}>50 \%$ or $P<0.1$. The MantelHaenszel fixed-effects model was used if there was no significant heterogeneity; otherwise, the Der Simonian and Laird random effects model was utilized. ${ }^{28}$ Subgroup analyses and logistic metaregression analyses were conducted to explore the source of heterogeneity between variables, such as cancer type, ethnicity, quantitative method, sample size, and study quality. Sensitivity analysis was carried out to identify the effect of data from each study on the pooled HRs. Publication bias was determined by Egger's test and Begg's funnel plots. $^{29}$ All statistical tests were conducted with STATA software version 12.0 (STATA Corporation, College Station, TX, USA), and $P<0.05$ was considered significant.

\section{Results Study characteristics}

In total, 262 potentially relevant studies were identified after the initial database searches. After a rough review of the titles and abstracts of all studies, 212 studies were excluded, then, with a systematical review of the full texts, another 34 studies were excluded (Figure 1). After further screening, one article was excluded because of insufficient data. ${ }^{10}$ Moreover, one study $^{22}$ included two different survival analyses separately. Therefore, 15 eligible studies of 1,464 patients were finally included in this meta-analysis. , $^{71-17,19-24}$

The main characteristics of the included studies are summarized in Tables 1 and 2. Of the 15 studies, $10(1,157$ patients: 79.0\%) were performed in Asia, ${ }^{11-17,21,23,24}$ and the remaining five studies (307 patients: $21.0 \%$ ) were conducted in Europe and America. ${ }^{7,19,20,22}$ All of these studies were retrospective in design. The malignant neoplasms assessed in these studies were colorectal cancer, ${ }^{15-17}$ gastric cancer, ${ }^{11-14}$ hepatocellular carcinoma, ${ }^{21-23}$ nasopharyngeal carcinoma, ${ }^{24}$ bladder cancer, ${ }^{19}$ ovarian cancer, ${ }^{20}$ and glioblastoma. ${ }^{7}$ Enzyme-linked immunosorbent assay was used in eight studies, 7,12,13,15,17,21,22 and immunohistochemistry was used in the remaining six studies. . $^{11,14,16,19,20,23,24}$ 
Table I Main characteristics of studies included in the meta-analysis

\begin{tabular}{|c|c|c|c|c|c|c|c|c|c|c|}
\hline Authors & $\begin{array}{l}\text { Publication } \\
\text { year }\end{array}$ & Case nationality & $\begin{array}{l}\text { Dominant } \\
\text { ethnicity }\end{array}$ & $\begin{array}{l}\text { Sample } \\
\text { size }\end{array}$ & $\begin{array}{l}\text { Mean } \\
\text { age }\end{array}$ & Malignant disease & $\begin{array}{l}\text { Survival } \\
\text { analysis }\end{array}$ & $\begin{array}{l}\text { Source } \\
\text { of HR }\end{array}$ & $\begin{array}{l}\text { Follow-up } \\
\text { months }\end{array}$ & $\begin{array}{l}\text { NOS } \\
\text { score }\end{array}$ \\
\hline $\begin{array}{l}\text { Jiang } \\
\text { et al }{ }^{15}\end{array}$ & 2015 & People's Republic of China & Asian & 89 & NA & Colorectal cancer & OS & Reported & NA & 7 \\
\hline $\begin{array}{l}\text { Zhao } \\
\text { et al" }\end{array}$ & 2014 & People's Republic of China & Asian & 255 & NA & Gastric cancer & OS & Reported & 300 & 7 \\
\hline Sun et $\mathrm{al}^{12}$ & 2014 & People's Republic of China & Asian & 102 & 59 & Gastric cancer & OS & SC & NA & 5 \\
\hline $\begin{array}{l}\text { Ozaki } \\
\text { et } \mathrm{al}^{21}\end{array}$ & 2014 & Japan & Asian & 64 & 71 & $\begin{array}{l}\text { Hepatocellular } \\
\text { Carcinoma }\end{array}$ & OS & Reported & 109 & 8 \\
\hline Lv et $\mathrm{al}^{13}$ & 2014 & People's Republic of China & Asian & 114 & NA & Gastric cancer & OS & Reported & 84 & 8 \\
\hline Yu et $\mathrm{al}^{24}$ & 2013 & People's Republic of China & Asian & 41 & 47.3 & $\begin{array}{l}\text { Nasopharyngeal } \\
\text { carcinoma }\end{array}$ & OS & Reported & NA & 5 \\
\hline $\begin{array}{l}\text { Roudnicky } \\
\text { et al' }\end{array}$ & 2013 & Switzerland & Caucasian & 40 & NA & Bladder cancer & RFS & SC & NA & 4 \\
\hline $\begin{array}{l}\text { Nault l } \\
\text { et } \mathrm{a}^{22}\end{array}$ & 2013 & France & Caucasian & 58 & NA & $\begin{array}{l}\text { Early hepatocellular } \\
\text { carcinoma }\end{array}$ & OS/RFS & SC & 30 & 7 \\
\hline $\begin{array}{l}\text { Nault2 } \\
\text { et } \mathrm{al}^{22}\end{array}$ & 2013 & France & Caucasian & 67 & NA & $\begin{array}{l}\text { Advanced hepatocellular } \\
\text { carcinoma }\end{array}$ & OS & Reported & 13.6 & 7 \\
\hline $\begin{array}{l}\text { El Behery } \\
\text { et } \mathrm{a}^{20}\end{array}$ & 2013 & Egypt & Caucasian & 100 & 50.1 & Ovarian cancer & OS & Reported & 36 & 8 \\
\hline Kim et $\mathrm{al}^{16}$ & 2012 & Korea & Asian & 143 & NA & Colon carcinoma & OS/RFS & Reported & 80.7 & 9 \\
\hline Liu et $\mathrm{al}^{14}$ & 2010 & People's Republic of China & Asian & 159 & 57.2 & Gastric cancer & OS & Reported & $\mathrm{III}$ & 7 \\
\hline Ji et $\mathrm{al}^{17}$ & 2010 & Korea & Asian & 100 & NA & Colorectal cancer & OS & Reported & NA & 6 \\
\hline $\begin{array}{l}\text { Maurage } \\
\text { et } \mathrm{al}^{7}\end{array}$ & 2009 & USA & Caucasian & 42 & NA & Glioblastomas & OS & SC & NA & 5 \\
\hline $\begin{array}{l}\text { Huang } \\
\text { et } \mathrm{a}^{23}\end{array}$ & 2009 & People's Republic of China & Asian & 90 & 51 & $\begin{array}{l}\text { Hepatocellular } \\
\text { carcinoma }\end{array}$ & OS & Reported & 50 & 8 \\
\hline
\end{tabular}

Abbreviations: NA, not available; NOS, Newcastle-Ottawa; OS, overall survival; RFS, recurrence-free survival; SC, survival curve.

\section{Meta-analysis}

\section{Endocan expression and OS}

Fourteen studies with a total of 1,424 patients provided survival results in the form of OS. As the heterogeneity was not statistically significant $\left(I^{2}=25.80 \%, P=0.176\right)$, the fixedeffects model was used to pool HRs. The result revealed that high endocan expression predicts poor OS in various carcinomas, with a pooled HR of 2.48 (95\% CI: 2.12-2.90, $P<0.001$ ) (Figure 2).

To determine the prognostic role of endocan in different cancers, studies were divided into subgroups by cancer types. The results indicated that high endocan expression

Table 2 HRs and 95\% Cls for patient survival (OS) in association with endocan expression in enrolled studies

\begin{tabular}{|c|c|c|c|c|c|c|c|}
\hline \multirow[t]{2}{*}{ Authors } & \multirow{2}{*}{$\begin{array}{l}\text { Publication } \\
\text { year }\end{array}$} & \multirow{2}{*}{$\begin{array}{l}\text { Detecting } \\
\text { method }\end{array}$} & \multirow{2}{*}{$\begin{array}{l}\text { Cutoff } \\
\text { value }\end{array}$} & \multicolumn{2}{|l|}{ Case number } & \multicolumn{2}{|l|}{ HR (95\% CI) } \\
\hline & & & & High expression & Low expression & OS & RFS \\
\hline Jiang et $\mathrm{a}^{15}$ & 2015 & ELISA & $68.4 \mathrm{pg} / \mathrm{mL}$ & 45 & 44 & $4.09(2.27-10.88) M$ & NA \\
\hline Zhao et al ${ }^{14}$ & 2014 & IHC & $1 \%$ & 64 & 191 & $1.719(1.103-3.028)$ M & NA \\
\hline Sun et $\mathrm{al}^{12}$ & 2014 & ELISA & $0.826 \mathrm{ng} / \mathrm{mL}$ & NA & NA & $1.912(0.991-3.688) \cup$ & NA \\
\hline Ozaki et $\mathrm{al}^{21}$ & 2014 & ELISA & $2.20 \mathrm{ng} / \mathrm{mL}$ & 48 & 16 & $2.36(1.22-5.36) \mathrm{M}$ & NA \\
\hline Lv et $\mathrm{al}^{13}$ & 2014 & ELISA & $84.2 \mathrm{pg} / \mathrm{mL}$ & NA & NA & $2.493(1.065-6.021) \mathrm{M}$ & NA \\
\hline Yu et $\mathrm{al}^{24}$ & 2013 & $\mathrm{IHC}$ & $10 \%$ & 21 & 20 & $3.140(1.078-9.142) \mathrm{M}$ & NA \\
\hline Roudnicky et al ${ }^{19}$ & 2013 & $\mathrm{IHC}$ & Score $\geq 2$ & 12 & 28 & NA & $\mathrm{I} .83(0.70-4.74) \mathrm{U}^{*}$ \\
\hline Naultl et $\mathrm{al}^{22}$ & 2013 & ELISA & $5 \mathrm{ng} / \mathrm{mL}$ & 23 & 35 & $\mathrm{I} .74(0.75-4.04) \mathrm{U}^{*}$ & $2.17(1.1-4.27) U^{*}$ \\
\hline Nault2 et al ${ }^{22}$ & 2013 & ELISA & $5 \mathrm{ng} / \mathrm{mL}$ & 38 & 29 & $\mathrm{I} .16$ (0.48-2.79) M & NA \\
\hline El Behery et $\mathrm{al}^{20}$ & 2013 & IHC & Score $\geq 73.5$ & NA & NA & $3.31(2.10-4.35) \mathrm{M}$ & NA \\
\hline Kim et $\mathrm{al}^{16}$ & 2012 & $\mathrm{IHC}$ & $25 \%$ & 76 & 67 & $3.53 \mathrm{I}(\mathrm{I} .632-7.644) \mathrm{M}$ & $2.109(1.196-3.716) \mathrm{M}$ \\
\hline Liu et al & 2010 & $\mathrm{IHC}$ & $25 \%$ & 92 & 67 & $1.88(1.15-3.08) M$ & NA \\
\hline Ji et al $^{17}$ & 2010 & ELISA & $76 \mathrm{pg} / \mathrm{mL}$ & NA & NA & $3.394(1.285-8.963) M$ & NA \\
\hline Maurage et $\mathrm{al}^{7}$ & 2009 & ELISA & NA & 15 & 27 & 1.68 (I.02-2.77) U* & NA \\
\hline Huang et $\mathrm{al}^{23}$ & 2009 & $\mathrm{IHC}$ & Score $\geq 73.5$ & NA & NA & $3.31(2.10-4.35) M$ & NA \\
\hline
\end{tabular}

Notes: The source of $\mathrm{HR}$ and $95 \% \mathrm{Cl}$ is described as derived from univariate analysis $(\mathrm{U})$ or multivariate analysis $(\mathrm{M})$. $* \mathrm{HR}$ and $95 \% \mathrm{Cl}$ calculated from survival curves. Abbreviations: $\mathrm{Cl}$, confidence intervals; ELISA, enzyme-linked immunosorbent assay; HR, hazard ratio; IHC, immunohistochemistry; NA, not available; OS, overall survival; RFS, recurrence-free survival. 


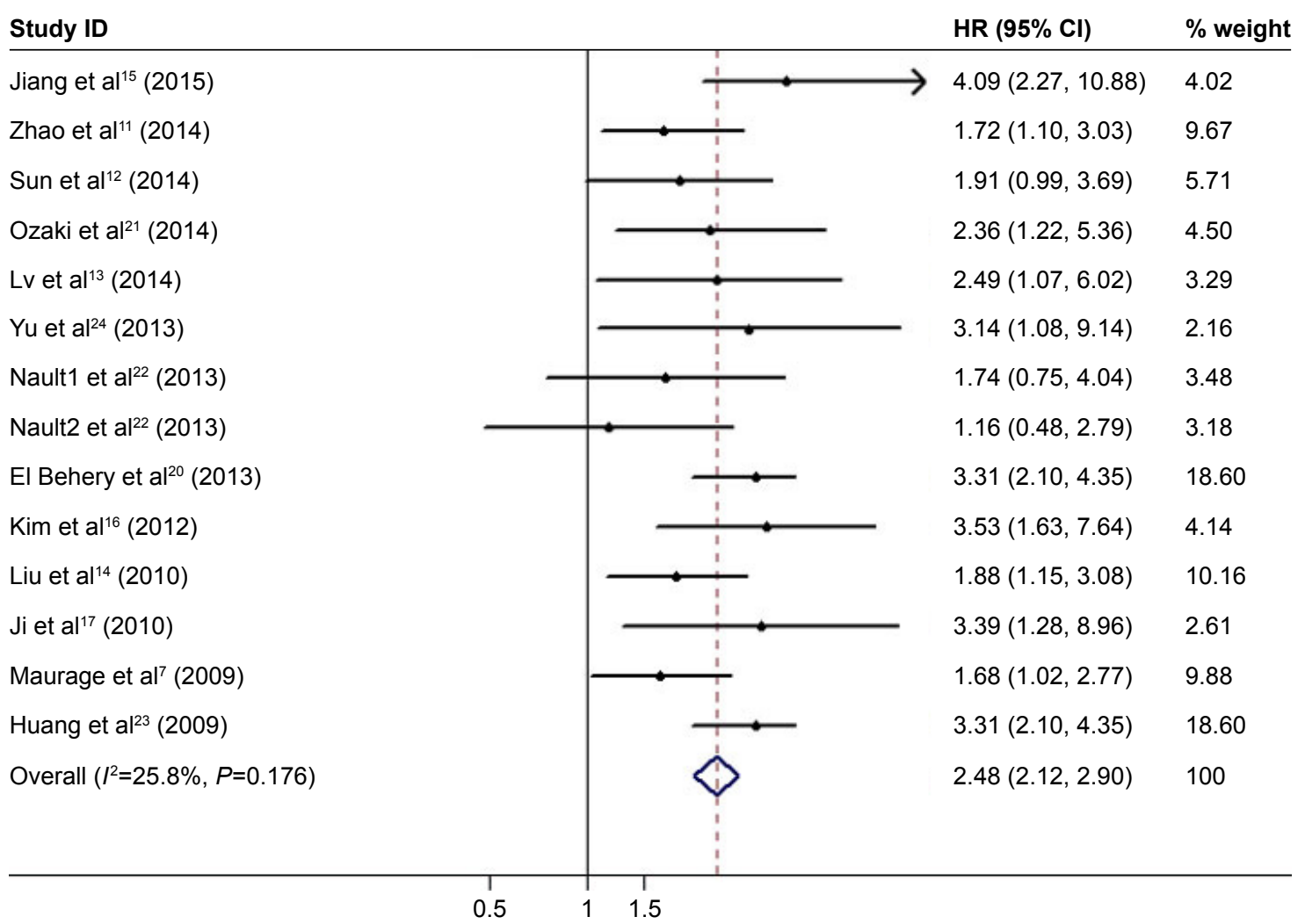

Figure 2 Forest plot of HRs for the association between high endocan expression and OS in patients with malignant tumors.

Abbreviations: HRs, hazard ratios; OS, overall survival.

was an unfavorable prognostic indicator in both gastrointestinal (HR: 2.27, 95\% CI: 1.77-2.91, $P<0.001$ ) and hepatocellular (HR: 2.61, 95\% CI: 1.96-3.48, $P<0.001$ ) carcinoma (Figure 3).

Subgroup analyses by ethnicity revealed that endocan was a negative predictor of OS for both Asian (HR: 2.56, 95\% CI: $2.11-3.11, P<0.001$ ) and Caucasian (HR: 1.99, 95\% CI: $1.22-3.26, P=0.006)$ populations. When considering differences in sample type, high endocan level was a poor prognostic marker for sera (HR: 2.08, 95\% CI: 1.61-2.70, $P<0.001)$ and tissue (HR: 2.74, 95\% CI: 2.25-3.34, $P<0.001)$. In addition, subgroup analyses showed that an elevated endocan level predicted poor prognosis, regardless of sample size and the study quality (Table 3 ).

\section{Endocan expression and RFS}

Three studies ${ }^{16,19,22}$ were used for RFS analysis with a fixedeffects model $\left(I^{2}=0.00 \%, P=0.958\right)$. Our results indicated that elevated endocan predicted a worse outcome for RFS, with a combined HR of 2.08 (95\% CI: 1.40-3.09, $P<0.001)$. Subgroup analysis, metaregression analysis, and sensitivity analysis were not applicable because of the limited number of studies.

\section{Sensitivity analysis}

We adopted the "leave-one-out" scheme (ie, analysis is conducted using all studies but one) to explore the influence of individual studies on the pooled HRs. The results showed that the pooled HRs were not materially altered, which suggested that no individual study significantly affected the pooled results (Figure 4).

\section{Publication bias}

Begg's funnel plot and the Egger's linear regression test were conducted to evaluate the publication bias of the literature. In the pooled analyses of OS and RFS, the Egger's test $P$-values were 0.466 and 0.372 , respectively, as shown by symmetric funnel plots (Figure 5). Therefore, no evidence of publication bias was noted.

\section{Discussion}

Endocan is a soluble dermatan sulfate (DS) proteoglycan, which is secreted by the vascular endothelium and freely circulates in the bloodstream. ${ }^{1}$ Accumulating evidence shows that endocan is related to the regulation of major processes such as cell adhesion, inflammatory disorders, and tumor progression. ${ }^{30-32}$ Inflammatory cytokines, such 


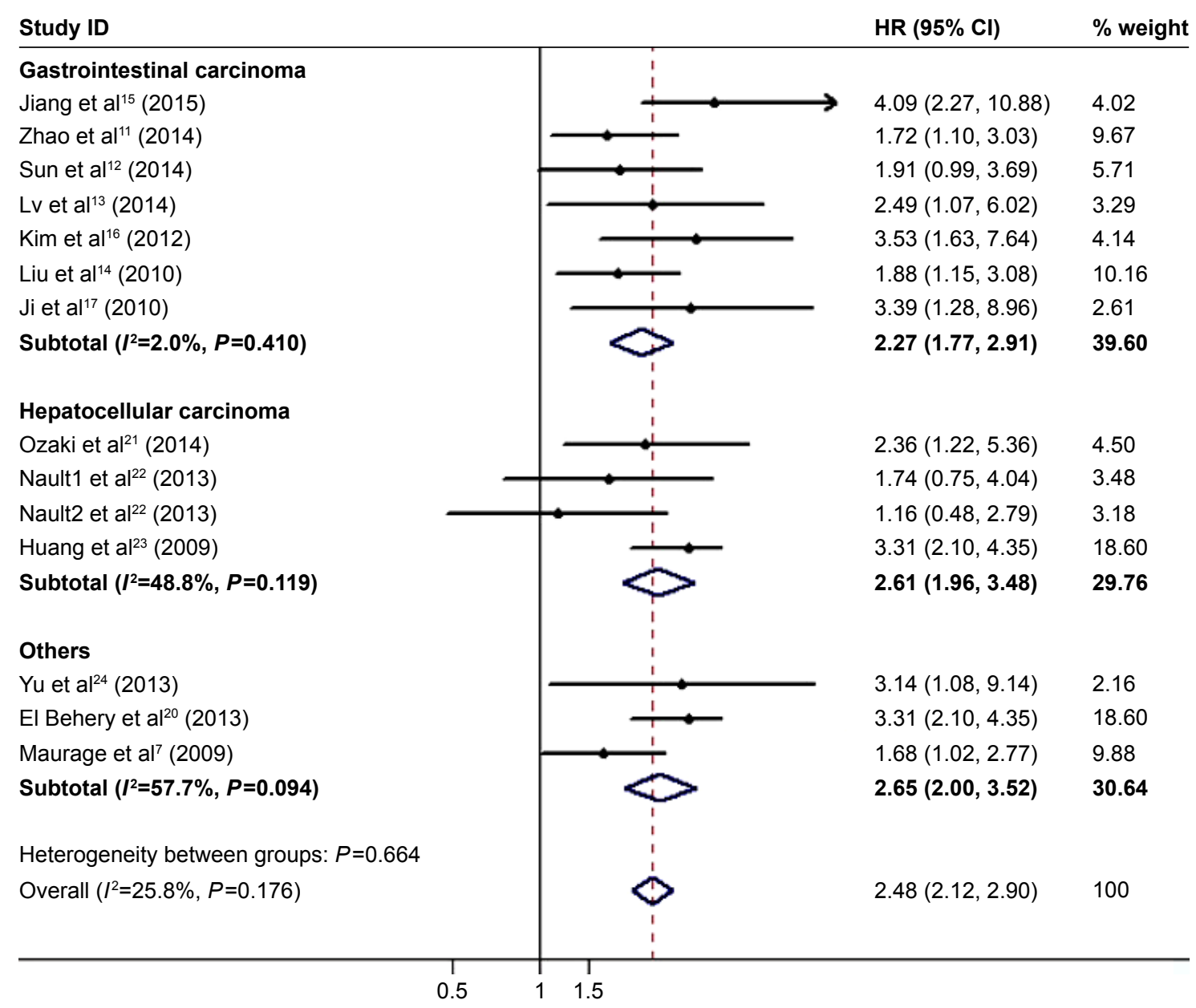

Figure 3 Meta-analysis (forest plot) of the evaluable studies assessing endocan expression and OS, stratified by cancer type. Abbreviation: OS, overall survival.

Table 3 Main results of meta-analysis

\begin{tabular}{|c|c|c|c|c|c|c|c|}
\hline \multirow[t]{2}{*}{ Categories } & \multirow[t]{2}{*}{ Studies } & \multirow[t]{2}{*}{ Patients } & \multirow[t]{2}{*}{ HRs } & \multirow[t]{2}{*}{$95 \% \mathrm{Cl}$} & \multicolumn{2}{|c|}{ Heterogeneity } & \multirow[t]{2}{*}{$P$-value } \\
\hline & & & & & $I^{2}(\%)$ & $\mathbf{P}_{\mathrm{h}}$ & \\
\hline Overall & 14 & $\mathrm{I}, 424$ & 2.48 & $2.12-2.90$ & 25.80 & 0.176 & $<0.001$ \\
\hline \multicolumn{8}{|l|}{ Cancer type } \\
\hline Gastrointestinal carcinoma & 7 & 962 & 2.27 & $1.77-2.91$ & 2.00 & $0.4 I$ & $<0.001$ \\
\hline Hepatocellular carcinoma & 4 & 279 & 2.61 & $1.96-3.48$ & 48.80 & 0.119 & $<0.001$ \\
\hline Others & 3 & 183 & 2.54 & $1.53-4.20$ & 57.70 & 0.094 & $<0.001$ \\
\hline \multicolumn{8}{|l|}{ Ethnicity } \\
\hline Asian & 10 & $\mathrm{I}, \mathrm{I} 57$ & 2.56 & $2.11-3.11$ & 1.40 & 0.426 & $<0.001$ \\
\hline Caucasian & 4 & 267 & 1.99 & $1.22-3.26$ & 62.90 & 0.044 & 0.006 \\
\hline \multicolumn{8}{|l|}{ Sample type } \\
\hline Sera & 8 & 636 & 2.08 & $1.61-2.70$ & 0.00 & 0.456 & $<0.001$ \\
\hline Tissue & 6 & 788 & 2.74 & $2.25-3.34$ & 38.00 & 0.153 & $<0.001$ \\
\hline \multicolumn{8}{|l|}{ Sample size } \\
\hline Large & 7 & 973 & 2.47 & $2.00-3.06$ & 19.60 & 0.28 & $<0.001$ \\
\hline Small & 7 & 451 & 2.49 & $1.97-3.14$ & 40.40 & 0.122 & $<0.001$ \\
\hline \multicolumn{8}{|l|}{ Study quality } \\
\hline High & II & 1,239 & 2.63 & $2.21-3.13$ & 28.40 & 0.175 & $<0.001$ \\
\hline Low & 3 & 185 & 1.89 & I.30-2.74 & 0.00 & 0.582 & $0.00 \mathrm{I}$ \\
\hline
\end{tabular}

Abbreviations: $\mathrm{Cl}$, confidence interval; $\mathrm{HRs}$, hazard ratios; $\mathrm{P}_{\mathrm{h}}, \mathrm{P}_{\text {Heterogeneity }}$ 


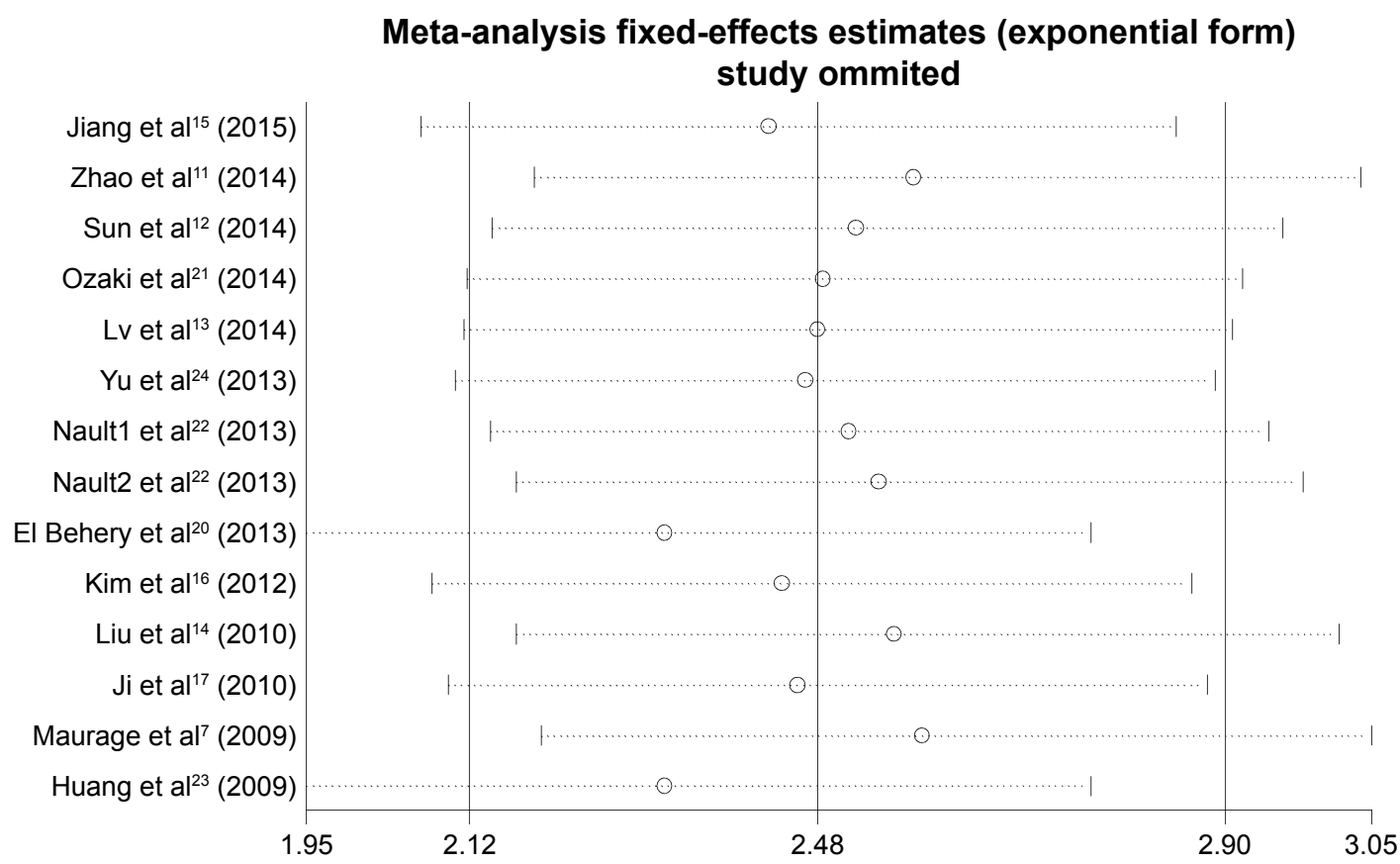

Figure 4 Sensitivity analysis for OS: effect of individual studies on pooled HRs for patients with cancer. Abbreviations: HRs, hazard ratios; OS, overall survival.

as tumor necrosis factor- $\alpha$ and interleukin-1, strongly increase the expression and secretion of endocan. ${ }^{1,4}$ Endocan also plays vital roles during angiogenesis. ${ }^{33}$ The study by Shin et $\mathrm{al}^{34}$ showed that endocan level is increased in endothelial cells treated with vascular endothelial growth factor-A, and that its expression can induce tumor formation. Moreover, treatment of cultured endothelial cells with anti-angiogenic drugs or multityrosine kinase inhibitors can abolish the vascular endothelial growth factor-induced secretion of endocan. ${ }^{35}$ Furthermore, Béchard et al reported

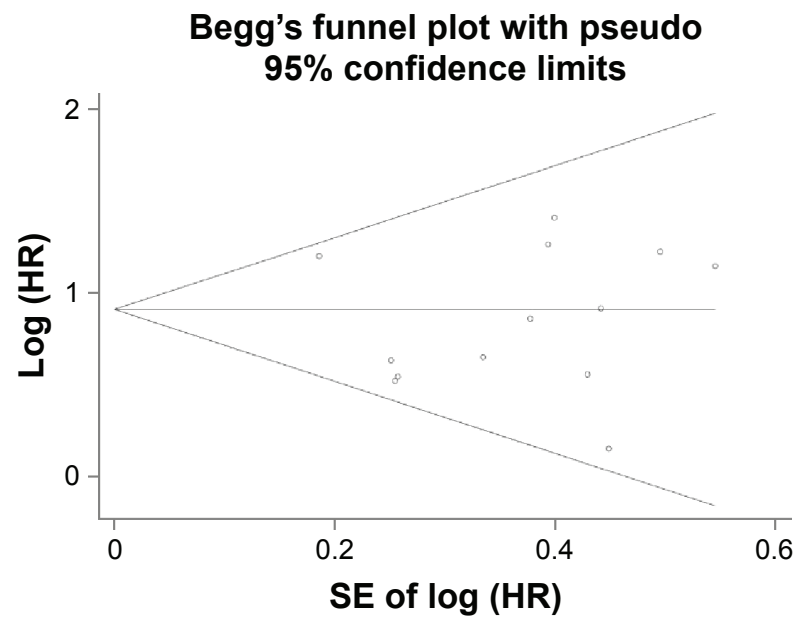

Figure 5 Begg's funnel plot of endocan expression and OS in patients with tumors.

Abbreviations: HR, hazard ratio; OS, overall survival; SE, standard error. a possible feedback mechanism in which tumor epithelial cells secrete growth factors that stimulate endothelial cell proliferation and endocan secretion, then endocan further stimulates tumor cell proliferation and secretion of growth factors and also promotes the proliferation of blood vessels. ${ }^{3}$ Based on these results, it would be of great interest to use endocan expression as a biomarker for the screening of patients susceptible to angiogenesis-targeted therapies and to explore the prognostic value of endocan in various types of cancer. ${ }^{7,11-17,19-24,36}$ However, the results remain controversial for many conditions. The aim of the current study was therefore to evaluate the prognostic value of endocan. To the best of our knowledge, this is the first meta-analysis to evaluate the correlation between endocan overexpression and survival in various cancers.

Meta-analysis is a useful tool to detect effects that may be missed by individual studies. ${ }^{37}$ In the current meta-analysis, we combined 15 publications on 1,464 patients to yield statistics, indicating a statistically significant role of endocan in cancers. Combined HRs suggested that elevated endocan significantly predicts poor OS (HR: $2.48,95 \%$ CI: $2.12-2.90$, $P<0.001$ ) and RFS (HR: $2.08,95 \%$ CI: $1.40-3.09, P<0.001$ ) in patients with cancer. In addition, the significance of this association was not changed in a sensitivity analysis that removed individual studies. Subgroup analyses showed that the trend toward worse OS with higher endocan level was present in both Asian and Caucasian patients. We performed 
subgroup analyses based on sample type, and found that patients with low endocan level had better OS compared with those with elevated endocan level, regardless of the sample type. Subgroup analysis stratified by sample size (ie, large or small) and study quality (ie, high or low) also revealed that endocan had a negative effect on OS.

To understand our findings better, some limitations should be considered. First, this meta-analysis was limited to articles published in English and Chinese and could not include studies that were not published because of negative or useless results. Second, our meta-analysis data did not include information on tumor stage, treatment, age, or physical condition, which might result in confounding bias. Third, immunohistochemistry was used as the detecting method in six studies, but it is a relatively complicated technique with many steps and is observer dependent. Fourth, some survival data were not presented directly, so we had to extract HR from survival curves in some enrolled studies, ${ }^{7,19}$ and these HRs and 95\% CIs might be less reliable than those given directly by the authors. Fifth, the applied methods for detecting endocan expression and the cutoff values were different in different studies, which could cause heterogeneity between the enrolled studies.

In conclusion, despite the limitations of the present study and heterogeneity across the included studies, our metaanalysis suggests that high endocan expression is negatively associated with prognosis of cancer. Future larger scale prospective and standard investigations should be conducted to confirm our results.

\section{Acknowledgments}

This research was supported by the Natural Science Foundation of China (81672869), National Science Foundation for Young Scholars (81302013), Jiangsu Provincial Science Foundation (BK20161596), and Jiangsu Provincial Six talent peak of Human affair Hall Funding (2013-WSW-037).

\section{Disclosure}

The authors report no conflicts of interest in this work.

\section{References}

1. Lassalle P, Molet S, Janin A, et al. ESM-1 is a novel human endothelial cell-specific molecule expressed in lung and regulated by cytokines. J Biol Chem. 1996;271(34):20458-20464.

2. Rennel E, Mellberg S, Dimberg A, et al. Endocan is a VEGF-A and $\mathrm{PI} 3 \mathrm{~K}$ regulated gene with increased expression in human renal cancer. Exp Cell Res. 2007;313(7):1285-1294.

3. Bechard D, Gentina T, Delehedde M, et al. Endocan is a novel chondroitin sulfate/dermatan sulfate proteoglycan that promotes hepatocyte growth factor/scatter factor mitogenic activity. J Biol Chem. 2001; 276(51):48341-48349.
4. Sarrazin S, Adam E, Lyon M, et al. Endocan or endothelial cell specific molecule-1 (ESM-1): a potential novel endothelial cell marker and a new target for cancer therapy. Biochim Biophys Acta. 2006; 1765(1):25-37.

5. Scherpereel A, Gentina T, Grigoriu B, et al. Overexpression of endocan induces tumor formation. Cancer Res. 2003;63(18):6084-6089.

6. Almog N, Ma L, Raychowdhury R, et al. Transcriptional switch of dormant tumors to fast-growing angiogenic phenotype. Cancer Res. 2009; 69(3):836-844.

7. Maurage CA, Adam E, Mineo JF, et al. Endocan expression and localization in human glioblastomas. J Neuropathol Exp Neurol. 2009; 68(6):633-641.

8. Cornelius A, Cortet-Rudelli C, Assaker R, et al. Endothelial expression of endocan is strongly associated with tumor progression in pituitary adenoma. Brain Pathol. 2012;22(6):757-764.

9. Matano F, Yoshida D, Ishii Y, Tahara S, Teramoto A, Morita A. Endocan, a new invasion and angiogenesis marker of pituitary adenomas. J Neurooncol. 2014;117(3):485-491.

10. Grigoriu BD, Depontieu F, Scherpereel A, et al. Endocan expression and relationship with survival in human non-small cell lung cancer. Clin Cancer Res. 2006;12(15):4575-4582.

11. Zhao W, Sun M, Li S, Wang Y, Liu J. Biological and clinical implications of endocan in gastric cancer. Tumour Biol. 2014;35(10): 10043-10049.

12. Sun W, Zhang L, Cheng X, et al. [Detection of serum endothelial cell specific molecule 1 in gastric cancer patients and its clinical significance]. Zhonghua Wei Chang Wai Ke Za Zhi. 2014;17(1):51-55. Chinese.

13. Lv Z, Fan Y, Chen H, Zhao D. Endothelial cell-specific molecule-1: a potential serum marker for gastric cancer. Tumour Biol. 2014;35(10): 10497-10502.

14. Liu N, Zhang LH, Du H, et al. Overexpression of endothelial cell specific molecule-1 (ESM-1) in gastric cancer. Ann Surg Oncol. 2010; 17(10):2628-2639.

15. Jiang H, Fu XG, Chen YT. Serum level of endothelial cell-specific molecule-1 and prognosis of colorectal cancer. Genet Mol Res. 2015; 14(2):5519-5526.

16. Kim JH, Park MY, Kim CN, et al. Expression of endothelial cell-specific molecule-1 regulated by hypoxia inducible factor-1alpha in human colon carcinoma: impact of ESM-1 on prognosis and its correlation with clinicopathological features. Oncol Rep. 2012;28(5):1701-1708.

17. Ji NY, Kim YH, Jang YJ, et al. Identification of endothelial cell-specific molecule-1 as a potential serum marker for colorectal cancer. Cancer Sci. 2010;101(10):2248-2253.

18. Leroy X, Aubert S, Zini L, et al. Vascular endocan (ESM-1) is markedly overexpressed in clear cell renal cell carcinoma. Histopathology. 2010;56(2):180-187.

19. Roudnicky F, Poyet C, Wild P, et al. Endocan is upregulated on tumor vessels in invasive bladder cancer where it mediates VEGF-A-induced angiogenesis. Cancer Res. 2013;73(3):1097-1106.

20. El Behery MM, Seksaka MA, Ibrahiem MA, Saleh HS, El Alfy Y. Clinicopathological correlation of endocan expression and survival in epithelial ovarian cancer. Arch Gynecol Obstet. 2013;288(6):1371-1376.

21. Ozaki K, Toshikuni N, George J, et al. Serum endocan as a novel prognostic biomarker in patients with hepatocellular carcinoma. J Cancer. 2014;5(3):221-230.

22. Nault JC, Guyot E, Laguillier C, et al. Serum proteoglycans as prognostic biomarkers of hepatocellular carcinoma in patients with alcoholic cirrhosis. Cancer Epidemiol Biomarkers Prev. 2013;22(8):1343-1352.

23. Huang GW, Tao YM, Ding X. Endocan expression correlated with poor survival in human hepatocellular carcinoma. Dig Dis Sci. 2009; 54(2):389-394.

24. Yu PH, Chou SF, Chen CL, et al. Upregulation of endocan by EpsteinBarr virus latent membrane protein 1 and its clinical significance in nasopharyngeal carcinoma. PLoS One. 2013;8(12):e82254.

25. Moher D, Liberati A, Tetzlaff J, Altman DG; PRISMA Group. Preferred reporting items for systematic reviews and meta-analyses: the PRISMA statement. Int J Surg. 2010;8(5):336-341. 
26. Stang A. Critical evaluation of the Newcastle-Ottawa scale for the assessment of the quality of nonrandomized studies in meta-analyses. Eur J Epidemiol. 2010;25(9):603-605.

27. Tierney JF, Stewart LA, Ghersi D, Burdett S, Sydes MR. Practical methods for incorporating summary time-to-event data into metaanalysis. Trials. 2007;8:16.

28. DerSimonian R, Laird N. Meta-analysis in clinical trials revisited. Contemp Clin Trials. 2015;45(Pt A):139-145.

29. Egger M, Davey Smith G, Schneider M, Minder C. Bias in meta-analysis detected by a simple, graphical test. BMJ. 1997;315(7109):629-634.

30. Cox LA, van Eijk LT, Ramakers BP, et al. Inflammation-induced increases in plasma endocan levels are associated with endothelial dysfunction in humans in vivo. Shock. 2015;43(4):322-326.

31. Cimen T, Efe TH, Akyel A, et al. Human endothelial cell-specific molecule-1 (Endocan) and coronary artery disease and microvascular angina. Angiology. 2016;67(9):846-853.

32. Delehedde M, Devenyns L, Maurage CA, Vives RR. Endocan in cancers: a lesson from a circulating dermatan sulfate proteoglycan. Int J Cell Biol. 2013;2013:705027.
33. Yang J, Yang Q, Yu S, Zhang X. Endocan: a new marker for cancer and a target for cancer therapy. Biomed Rep. 2015;3(3):279-283.

34. Shin JW, Huggenberger R, Detmar M. Transcriptional profiling of VEGF-A and VEGF-C target genes in lymphatic endothelium reveals endothelial-specific molecule-1 as a novel mediator of lymphangiogenesis. Blood. 2008;112(6):2318-2326.

35. Chen LY, Liu X, Wang SL, Qin CY. Over-expression of the endocan gene in endothelial cells from hepatocellular carcinoma is associated with angiogenesis and tumour invasion. $J$ Int Med Res. 2010;38(2): 498-510.

36. Ziol M, Sutton A, Calderaro J, et al. ESM-1 expression in stromal cells is predictive of recurrence after radiofrequency ablation in early hepatocellular carcinoma. J Hepatol. 2013;59(6):1264-1270.

37. Timulak L. Meta-analysis of qualitative studies: a tool for reviewing qualitative research findings in psychotherapy. Psychother Res. 2009; 19(4-5):591-600.
OncoTargets and Therapy

\section{Publish your work in this journal}

OncoTargets and Therapy is an international, peer-reviewed, open access journal focusing on the pathological basis of all cancers, potential targets for therapy and treatment protocols employed to improve the management of cancer patients. The journal also focuses on the impact of management programs and new therapeutic agents and protocols on

\section{Dovepress}

patient perspectives such as quality of life, adherence and satisfaction The manuscript management system is completely online and includes a very quick and fair peer-review system, which is all easy to use. Visit http://www.dovepress.com/testimonials.php to read real quotes from published authors. 